\title{
APLICAÇÃO DA SIMULAÇÃO COMPUTACIONAL NO MAPEAMENTO DO PROCESSO DE ENTREGA DE MEDICAMENTOS: UM ESTUDO DE CASO EM UMA REDE DE FARMÁCIAS NO TRIÂNGULO MINEIRO
}

\author{
Fernando de Araújo (UFG) faraujo@ufg.br \\ Fernando Lourenço de Souza (UFU) fernandosouza@ufu.br \\ Fernanda Pereira Oliveira (UFU) fernandacross@ hotmail.com \\ Luis Fernando Magnanini de Almeida (UFU) almeida@ufu.br \\ Hialisson Arantes (UFU) $\underline{\text { h_arantes01@yahoo.com.br }}$
}

\section{Resumo}

O presente trabalho tem como objetivo apresentar uma pesquisa detalhada dos processos logísticos de entrega de medicamentos mapeados desde o pedido do cliente na central de pedidos até a liberação para entrega no local informado pelo cliente. O mapeamento foi feito de modo que na análise seja associada a um sistema de modelagem e simulação discreta correlacionados entre si, que possam validar as hipóteses geradas pelo banco de dados diário de tempos de serviços, assim gerar mais valor na cadeia de relação entre o cliente e a empresa. Foi usada a ferramenta Anylogic versão 8.3.2, software de simulação multi-método baseado em eventos discretos, agentes e sistemas dinâmicos. Por fim, como resultados obtidos teve-se a melhoria dos processos utilizando as ferramentas necessárias em uma rede de farmácia na central de entregas reduzindo o tempo de entrega e as reentregas por alguma divergência de informações.

Palavras-Chaves: Logística; Modelagem; Mapeamento de Processos; Simulação discreta de sistema; Anylogic.

\section{Introdução}

O cenário que contextualiza a construção deste estudo remete preocupação com a satisfação do cliente, bem como a gestão de processos. O setor de logística, em especial o de entrega de produtos até o destino do cliente, tem se tornado um diferencial nas empresas que decidem por esse caminho, e estão, na maioria dos casos, cientes dos desafios que irão enfrentar, tais como, criar ou terceirizar sua frota, aumento de pessoal, aumento da taxa de ocupação e serviço dos responsáveis diretos no processo. Tudo isso indica aumento de pessoal, equipamentos e insumos. Analisar as fases do processo consiste em encontrar os gargalos de serviços e eliminá-los de forma que atenda a necessidade da empresa e de todos os envolvidos, bem como, a percepção do cliente final que está preocupado apenas com o tempo 
de entrega do pedido realizado na central de atendimento, tão quanto à forma e qualidade que o produto chegou ao seu destino conforme o combinado.

Nesse sentido, o presente trabalho, discute as ações de melhoria em um setor de entregas em uma rede farmacêutica situada no Triângulo Mineiro, a qual possui uma frota terceirizada e aproximadamente 15 colaboradores ligados diretamente no processo logístico, desde o pedido até a entrega ao cliente. Diante do contexto e vista a necessidade de estudo do assunto, o seguinte trabalho tem como objetivo geral, estudar o processo de entrega, desde a solicitação do pedido na central de atendimento até a entrega do produto na residência do cliente, abordando assim os indicadores que norteiam essas atividades. Especificamente os objetivos correspondem a realizar o mapeamento do processo operacional do setor de entregas, levantar dados referentes ao tempo de entrega do setor estudado, identificar os principais gargalos operacionais, analisar os indicadores logísticos do setor de entrega e propor sugestões de melhorias.

\section{Revisão Bibliográfica}

\subsection{Mapeamento de Processos}

O mapeamento de processo é simplesmente a descrição das relações entre as atividades dentro do processo. (SLACK; CHAMBERS; JOHNSTON, 2009).

Segundo Laurindo e Rotondaro (2006), uma das tarefas mais importantes na gestão por processos é o mapeamento de processos, onde permite maiores detalhes das operações que ocorrem para a produção de um serviço ou a fabricação de um produto. $\mathrm{O}$ mapeamento de processo é utilizado para o aperfeiçoamento dos processos, o qual este possui uma visualização de fácil análise, a partir do detalhamento do mesmo.

É de extrema importância que o levantamento das tarefas seja feito no local de trabalho e que as pessoas que estiverem envolvidas sejam entrevistadas (PALADINI, 2012).

De acordo com Paladini (2012), os responsáveis pelo mapeamento de processos necessitam conhecer os conceitos do sistema e do processo, os elementos do FEPSC (fornecedor, entrada, processo, saída, cliente), estarem aptos a aplicá-los a seu próprio processo, saber quais os valores para o cliente e para a empresa e entender como analisar os resultados obtidos no processo para identificar onde uma melhoria deve ter maior impacto. 
O primeiro procedimento é a definição das fronteiras do processo, onde começa e onde terminam as tarefas (PALADINI, 2012). A técnica usada é a FEPSC, ela ilustra os fornecedores, as entradas, o processo, as saídas e os clientes, como é lustrado na Figura 1.

Figura 1 - Representação de FEPSC

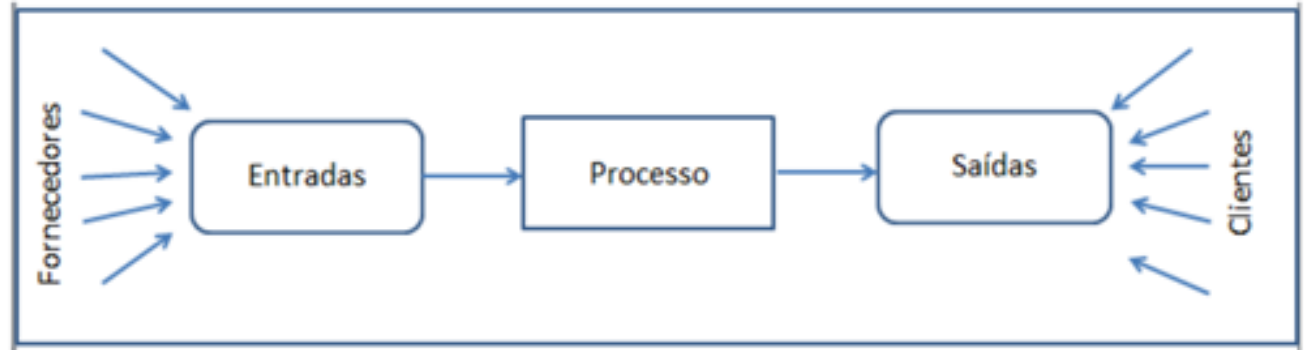

Fonte: PALADINI (2012)

\subsection{Gestão da Qualidade}

Para Carpinetti (2010), qualidade é o grau de satisfação das necessidades do usuário em relação ao produto em uso. Com a abertura do mercado exterior e assim, a entrada de produtos estrangeiros, os consumidores passaram a ser mais exigentes quanto à qualidade dos produtos adquiridos (MELLO, 2011). Melo (2011) destaca três fatores que estão diretamente ligados ao conceito de qualidade, sendo: Redução de custos, Aumento de produtividade, e Satisfação dos clientes.

\subsection{Ferramentas da Qualidade}

Para Mello (2011), existem várias ferramentas e métodos para que o controle de qualidade exercido durante o processo produtivo se efetive. $\mathrm{O}$ estudo desde a coleta de dados até à análise das causas da variabilidade de um processo, com base estatística, são as ferramentas ligadas ao controle de qualidade. De acordo com Paladini (2012), as ferramentas são métodos que viabilizam a definição de melhorias que possam ser implantadas em partes do processo produtivo. Ainda para Paladini (2012) as ferramentas da qualidade são conhecidas como: Diagrama de Ishikawa, Diagrama de Pareto, Fluxograma, Folha de Verificação, Gráfico de Controle, Gráfico de Dispersão e Histograma. Para o presente trabalhou aplicou-se as seguintes ferramentas: Diagrama de Ishikawa, Fluxograma e Gráfico de Controle. 


\subsection{Modelagem de Processo}

A definição de modelo é a representação hipotética de um processo, e analisa as relações entre as variáveis controláveis e incontroláveis, de uma rede de interações em estado dinâmico. (BERNARDI, 2009). A modelagem de processo é a construção de diagramas operacionais sobre o comportamento de um ou vários processos dentro de uma organização. (OLIVEIRA; ALMEIDA NETO, 2009).

\section{Metodologia}

Esta pesquisa foi desenvolvida utilizando-se do método indutivo, que é o processo que parte de dados particulares para inferir uma verdade geral ou universal, cujo objetivo é levar a conclusões sobre algum problema levantado na pesquisa. (MARCONI; LAKATOS, 2003). De acordo com Marconi e Lakatos (2003), a pesquisa bibliográfica se justifica, por abranger a bibliografia já tornada pública em relação ao tema estudando, incluindo livros, revistas, artigos científicos, teses, dentre outros, colocando o pesquisador em contato direto com tudo o que foi publicado sobre o assunto. Além da pesquisa bibliográfica, foi realizada pesquisa de campo, tendo como campo de estudo o setor de entregas de uma rede de farmácia situada no Triângulo Mineiro, buscando identificar aspectos do atual modelo produtivo da empresa, passíveis de melhorias e para os quais, a implementação de modelos de otimização capazes de ordenar toda cadeia produtiva que norteiam o setor de entregas, para que sejam eficientes na maximização dos resultados operacionais, comerciais e financeiros.

\section{Resultados e Discussão}

\subsection{Mapeamento do Processo Operacional do Setor de Entregas}

O setor de entregas conta com um fluxograma diversificado e com diversos indicadores. Tudo inicia no setor de televendas que emite o pedido do cliente via sistema que gera uma comanda de pedido, o qual é destinado ao setor de entregas por ordem de pedidos, os quais o colaborador que tem a função de imprimir essa comanda faz o que se chama internamente frente de loja, onde este separa os pedidos corretamente, para assim emitir o cupom fiscal, em seguida separando o pedido por bairro. Na Figura 2, encontra-se o fluxograma do pedido a partir do setor televendas, demonstrando as fases do pedido dentro da loja até a saída para a entrega no local informado pelo cliente. 
Figura 2 - Fluxograma do Televendas

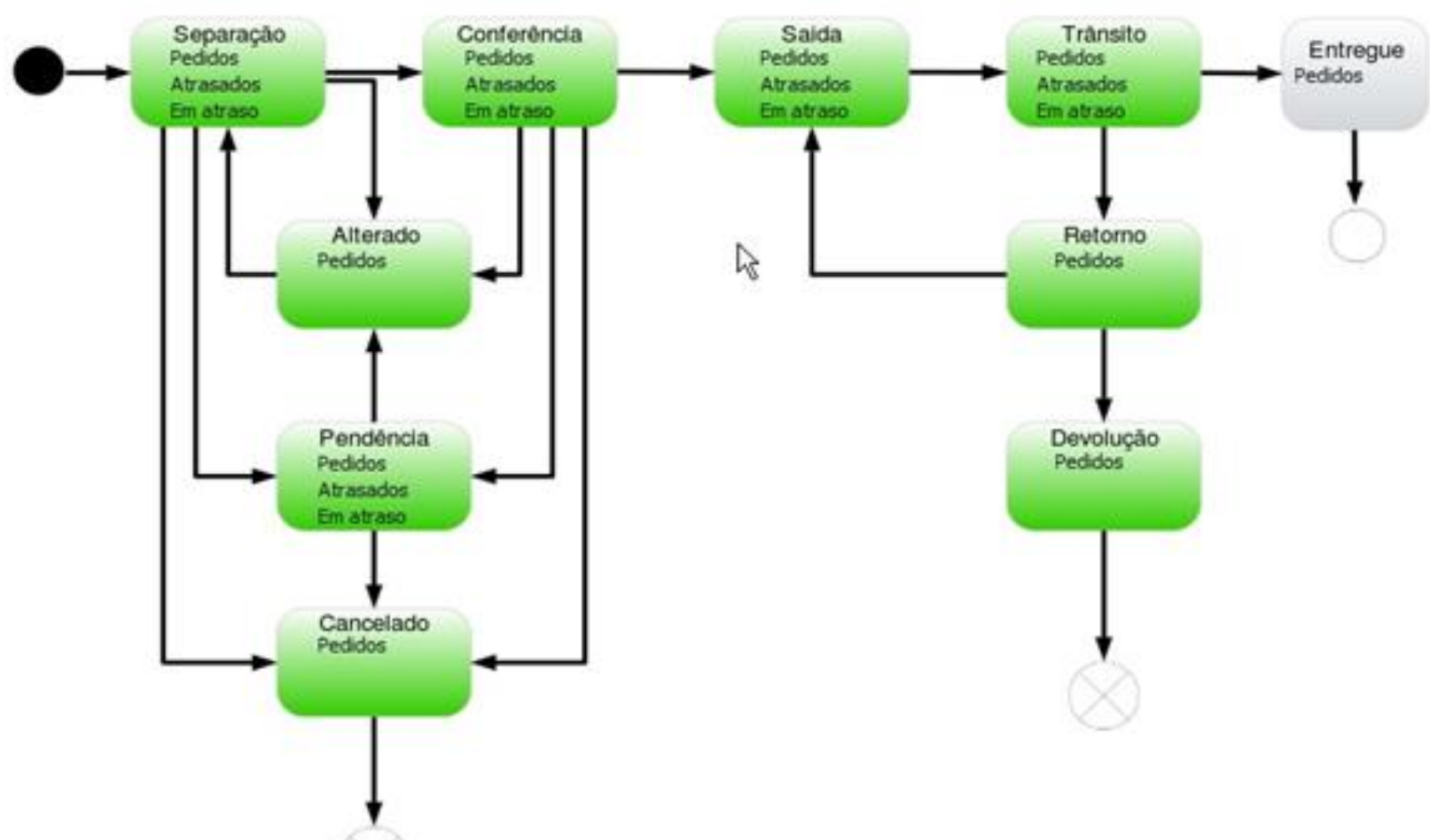

Fonte: Autoria Própria

\subsection{Levantamento dos Dados do Setor de Entregas}

Para tanto foi necessário levantar as demandas do setor de entregas, tais como, tempo de separação, confecção, mensurar o tempo de espera de um pedido dentro da loja e por fim o tempo final de entrega do pedido na casa do cliente. Os dados foram inseridos no Excel e como ferramenta quantitativa, avaliaram-se as etapas descritas em cada comanda de pedido, descrevendo assim os tempos de cada processo. Com isso notou-se uma configuração desfavorável à empresa, tais como: o tempo em que o pedido demorava dentro da loja era em torno de 1:15 horas e o tempo de entrega do pedido para o cliente estava em torno de 1:40 horas ou até 2:00 horas.

Foi mapeado um período de atividade no setor de entregas em torno de 40 dias, para levantar os indicadores que faziam com que as entregas demorassem para serem entregues na casa do cliente. Foram coletados mais de 6.500 dados de horas de entrega da farmácia. A média geral de todos eram lineares. Portanto foi necessário tratar esses dados e mensurar todos nos quesitos que norteiam a logística de entrega até ao cliente. Foram encontrados as seguintes causas e efeitos no setor de entregas, assim como mostra a Figura 3. 
Figura 3 - Diagrama de Ishikawa do setor de entregas

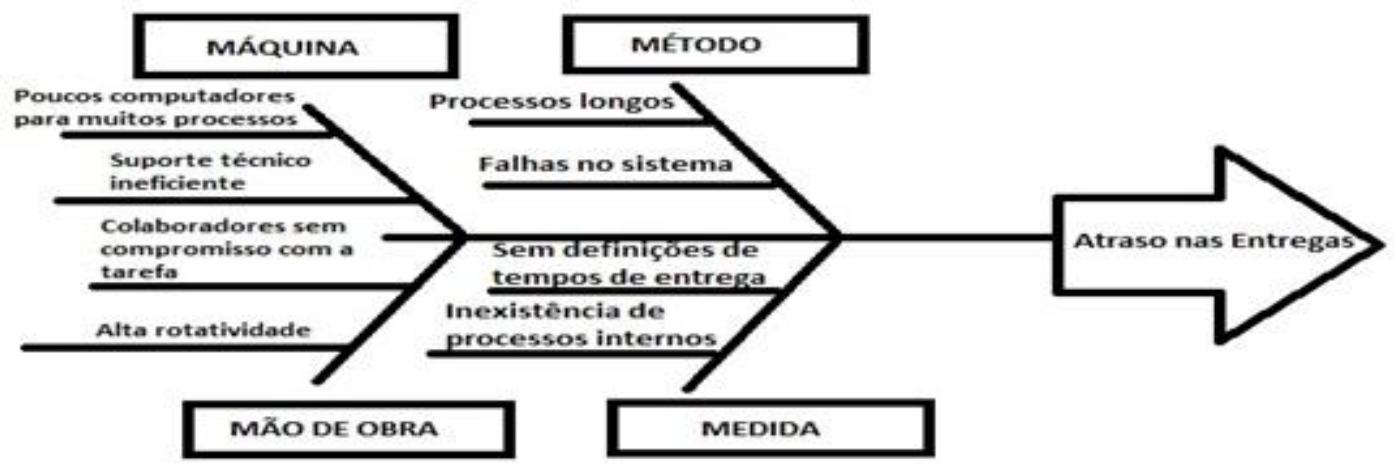

Fonte: Autoria Própria

\subsubsection{Métrica para coleta de dados do processo de entrega}

O Excel foi à ferramenta adotada para coletar os dados dos processos de entrega desde quando o cliente liga no setor e o pedido chega à casa do mesmo. Os dados foram coletados manualmente e transcritos diretamente nas planilhas. Teve o intuito exclusivamente para formar um banco de dados quantitativo para que assim permitisse flexibilizar o manuseio dos dados, de forma que ficariam mais expostos os indicadores necessários para este trabalho, conforme exemplo na Tabela 1 que trata se da base de dados de coleta do setor de entrega, bem como os processos que norteiam essa atividade. Em um único dia foram registradas 177 entregas. Todos os requisitos para o atendimento, como análise dos processos e indicadores foram coletados, de forma que, a Tabela 1 trata-se de uma pequena amostra, simplesmente para apresentar a organização dos dados coletados, num total de 6.500 (seis mil e quinhentos) dados, coletados num período de 4 meses de forma manual.

Tabela 1 - Coleta de dados do setor de entrega

\begin{tabular}{|c|c|c|c|c|c|c|c|c|c|c|c|c|}
\hline \multicolumn{13}{|c|}{ CENTRAL DE ENTREGAS } \\
\hline \multicolumn{13}{|c|}{ TODOS OS SETORES } \\
\hline Código & $\begin{array}{c}\text { Aguard. } \\
\text { Sep. }\end{array}$ & $\begin{array}{l}\text { Em } \\
\text { Sep. }\end{array}$ & $\begin{array}{c}\text { Processo } \\
1\end{array}$ & Checkout & Conf. & $\begin{array}{c}\text { Processo } \\
2\end{array}$ & Saída & Retorno & $\begin{array}{c}\text { Processo } \\
\mathbf{3}\end{array}$ & $\begin{array}{l}\text { Tempo } \\
\text { de } \\
\text { Aguard. } \\
\text { Sep. À } \\
\text { Conf. }\end{array}$ & $\begin{array}{c}\text { Tempo } \\
\text { de } \\
\text { espera } \\
\text { na } \\
\text { cesta }\end{array}$ & $\begin{array}{c}\text { Tempo } \\
\text { Total }\end{array}$ \\
\hline 124961 & 08:07 & 08:09 & 00:02 & 08:09 & 08:12 & 00:03 & 08:37 & 09:20 & $00: 43$ & 00:05 & $00: 25$ & $00: 30$ \\
\hline 124962 & 08:15 & 08:17 & 00:02 & 08:19 & 08:19 & 00:00 & 08:37 & 09:20 & $00: 43$ & 00:04 & 00:18 & $00: 22$ \\
\hline 124965 & 08:24 & 08:25 & 00:01 & 08:25 & 08:31 & 00:06 & 08:37 & 09:20 & 00:43 & 00:07 & 00:06 & 00:13 \\
\hline 124967 & 08:27 & 08:27 & 00:00 & 08:32 & 08:34 & 00:02 & 08:37 & 09:20 & 00:43 & 00:07 & 00:03 & 00:10 \\
\hline 124963 & 08:23 & 08:23 & 00:00 & 08:25 & 08:27 & 00:02 & 08:39 & 09:20 & 00:41 & 00:04 & 00:12 & 00:16 \\
\hline 124966 & 08:25 & 08:26 & 00:01 & 08:32 & 08:33 & 00:01 & 08:39 & 09:20 & 00:41 & 00:08 & 00:06 & 00:14 \\
\hline 124968 & 08:37 & 08:41 & 00:04 & 08:43 & 08:45 & 00:02 & 09:22 & $10: 40$ & 01:18 & 00:08 & 00:37 & $00: 45$ \\
\hline 124973 & 08:58 & 08:58 & 00:00 & 09:04 & 09:19 & 00:15 & 09:22 & $10: 40$ & 01:18 & $00: 21$ & 00:03 & $00: 24$ \\
\hline 124975 & 09:10 & 09:11 & 00:01 & 09:11 & 09:15 & 00:04 & 09:22 & $10: 40$ & 01:18 & $00: 05$ & 00:07 & $00: 12$ \\
\hline 124977 & 09:14 & 09:17 & 00:03 & 09:20 & 09:21 & 00:01 & 09:22 & $10: 40$ & 01:18 & 00:07 & 00:01 & 00:08 \\
\hline 124969 & 08:42 & 08:44 & 00:02 & 08:46 & 08:47 & 00:01 & 09:25 & $10: 40$ & 01:15 & 00:05 & 00:38 & 00:43 \\
\hline 124961 & 08:07 & 08:09 & $00: 02$ & 08:09 & 08:12 & 00:03 & 08:37 & 09:20 & $00: 43$ & $00: 05$ & $00: 25$ & 00:30 \\
\hline
\end{tabular}

Fonte: Autoria Própria 
De acordo com a Tabela 1, foi possível mensurar as etapas mais relevantes do processo de entrega.

- Aguardando separação: período compreendido entre o pedido do cliente até o início da separação do pedido;

- Em Separação: gerou se uma comanda de pedido no setor de entregas, neste momento este foi impresso;

- Checkout: conferência do que foi pedido com os dados da comanda;

- Conferência: Separação do pedido na frente da loja, ou seja, escolher na loja o que o cliente solicitou. Em seguida, emite se o cupom fiscal e coloca se na cesta pertinente ao setor da cidade que será entregue o pedido;

- Retorno: tempo fechado no sistema, assim quando o entregador chega no setor de entrega para acerto de contas com o colaborador do caixa;

- Aguardando separação e conferência: média que o pedido fica no setor desde a ligação do cliente até o termino da separação e disposição na cesta de saída;

- Tempo de espera na cesta: é o tempo que o pedido fica parado no setor aguardando algum entregador chegar. Esse processo é iniciado quando o colaborador termina a conferência;

- Tempo total: é o tempo que todo processo leva, ou seja, da ligação do cliente no setor de atendimento ao cliente até a entrega do pedido;

Os processos 1, 2 e 3 referem se a média de tempo gasto entre uma atividade e outra. Os indicadores listados na Tabela 1 deram início ao estudo de demanda de tempo da entrega.

\subsection{Modelo Ótimo para o Setor de Entregas}

São em média 220 entregas/dia, distribuídas em todos os setores da cidade. Após o levantamento de dados factíveis durante 60 dias, foi possível testar um modelo ótimo de rota de entregas, primeiramente foi necessário estudar os bairros da cidade e levantar uma média de pedidos e a frequência. Dividiu-se então a cidade em 4 setores distintos e o centro da cidade. Esta divisão foi proposta pelos entregadores, de deixar o centro no meio, com o intuito de que os pedidos da região central qualquer entregador pode fazer, pois é uma demanda baixa e tem como transitar entre os outros setores. A Figura 4 apresenta como ficaram organizados os setores. 
Figura 4 - Divisão dos bairros conforme demandas

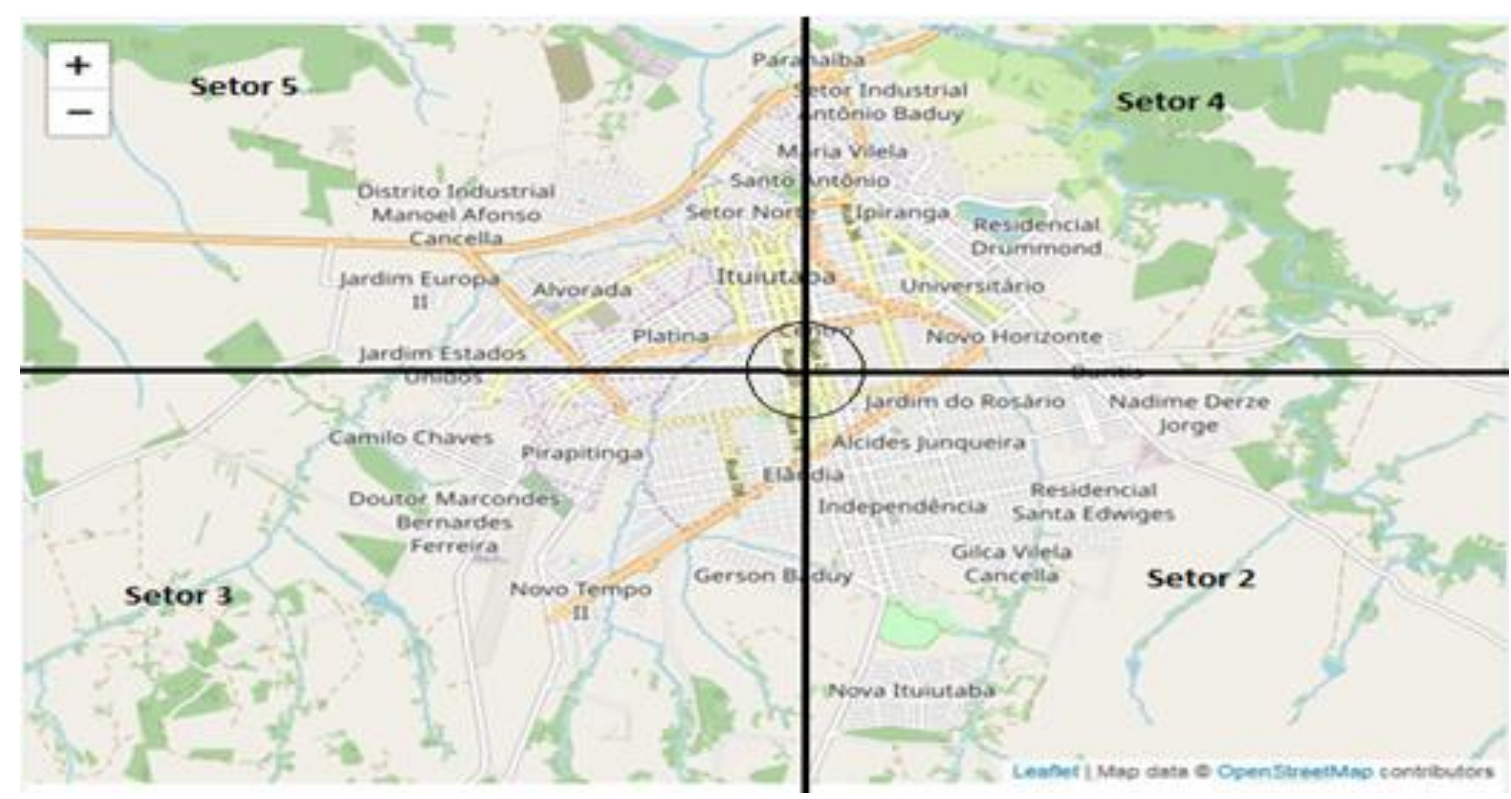

Fonte: Autoria Própria

\subsection{Modelando os Processos}

Foi utilizado o software Anylogic ${ }^{\circledR}$ para a realização de vários cenários para análise a fim de melhorar os gargalos descritos. A Figura 5 mostra o processo dentro da loja, quando o pedido fica aguardando a separação após ser realizado pelo televendas.

Figura 5 - Processo Interno da farmácia

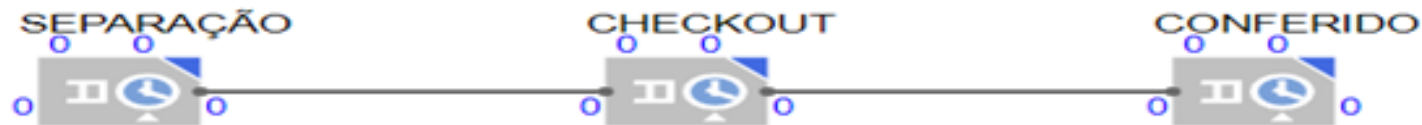

Fonte: Autoria Própria

No cenário do Anylogic ${ }^{\circledR}$ foi realizado este processo como um só, devido ser o mesmo colaborador a realizar todas as tarefas, somando assim, os tempos de cada atividade do processo dentro da loja para expressar o processo interno dos pedidos. O processo desde o televendas até o retorno do pedido na loja é mostrado na Figura 6.

Figura 6 - Processo do Pedido

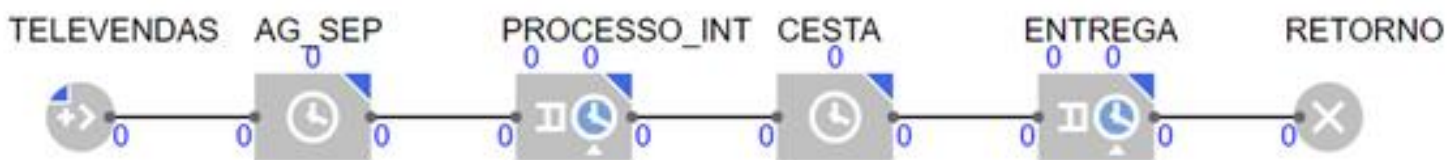

Fonte: Autoria Própria 
O primeiro cenário conta com dois entregadores e pode ser visualizado na Figura 7.

Figura 7 - Cenário 1: Dois entregadores

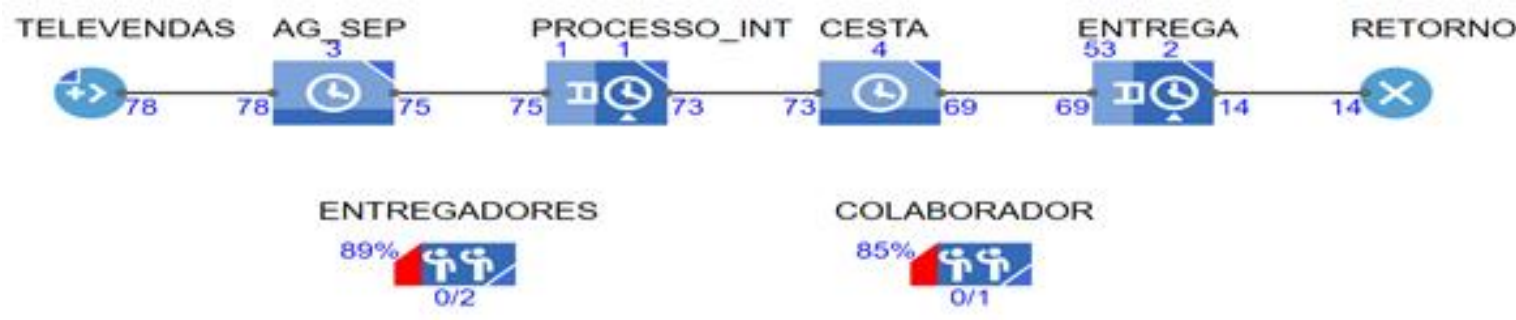

Fonte: Autoria Própria

Com 78 pedidos, 4 na cesta esperando pelos entregadores, 55 em trânsito e apenas 14 retornados à loja, temos uma porcentagem de $85 \%$ de ocupação do colaborador que realiza o processo interno, que é a separação, o checkout e a conferência dos pedidos e uma porcentagem de $89 \%$ de ocupação dos dois entregadores. O segundo cenário é testado com três entregadores, conforme a Figura 8.

Figura 8 - Cenário 2: Três entregadores

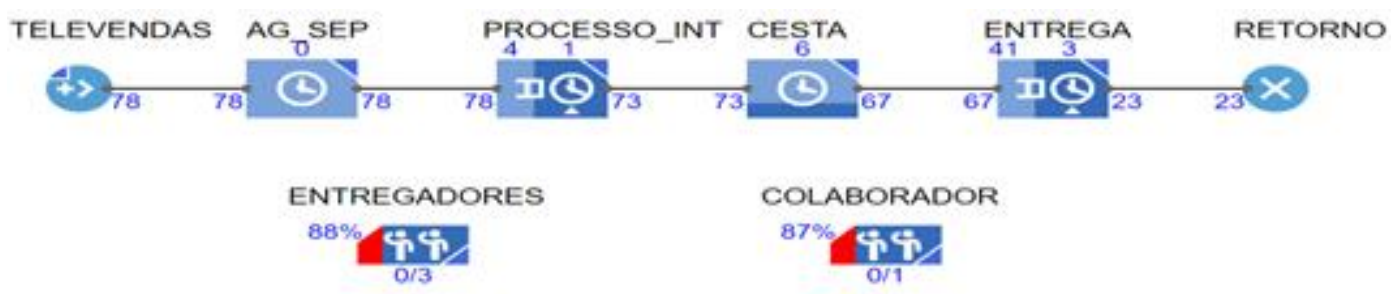

Fonte: Autoria Própria

Com 78 pedidos, 6 na cesta, 44 em trânsito e 23 retornados à loja, a taxa de ocupação do colaborador aumentou de 85 para $87 \%$ e a taxa dos entregadores diminuiu em $1 \%$, o que supõe que no primeiro cenário os dois entregadores estavam sobrecarregados, e agora tem menos pedidos em trânsito e mais pedidos retornados à loja, evidenciando a suposição que o terceiro entregador conseguiu diminuir o gargalo. Um terceiro cenário é feito, aumentando um colaborador no processo interno, como é mostrado na Figura 9.

Figura 9 - Cenário 3: Três entregadores e dois colaboradores

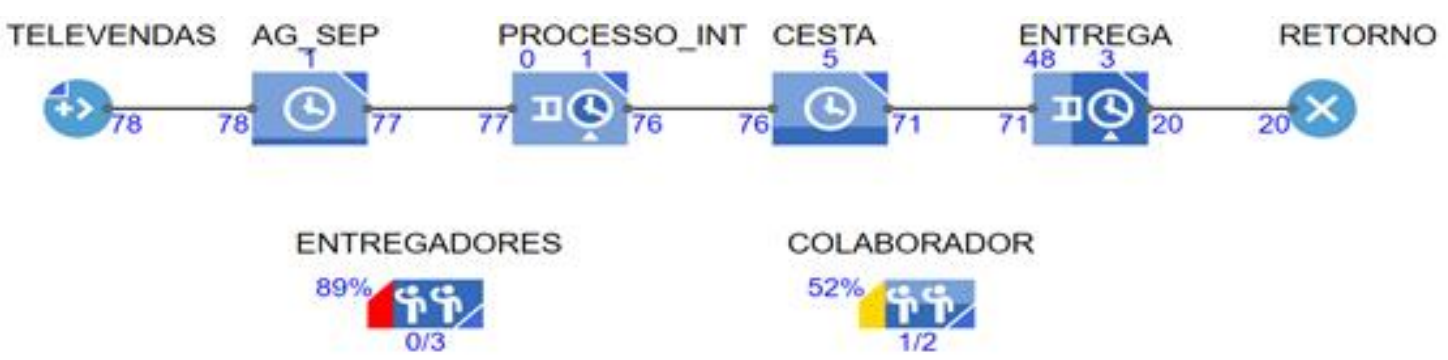

Fonte: Autoria Própria 
Neste cenário tem-se a chegada de 78 pedidos, 5 na cesta, 51 em trânsito e 20 retornados à loja. A taxa de ocupação dos colaboradores diminuiu radicalmente com o aumento de mais um colaborador. Portanto, o cenário 2 é o mais adequado, no qual foi trocado o horário de um entregador para ele suprir o gargalo das entregas, e com apenas um colaborador no processo, realizando com o mesmo treinamento para diminuir sua taxa de ocupação, visto que com dois colaboradores, a taxa é muito baixa.

\subsection{Análise Preliminar}

Foi gerado um mapa de coleta de dados manuais a uma planilha no Excel e mensurado esses tempos de um determinado dia com movimento expressivo de pedidos com todos os processos utilizando a base de dados da Tabela 1, obtendo assim os resultados conforme consta na Figura 10.

Figura 10 - Coleta de dados de solicitação de pedidos

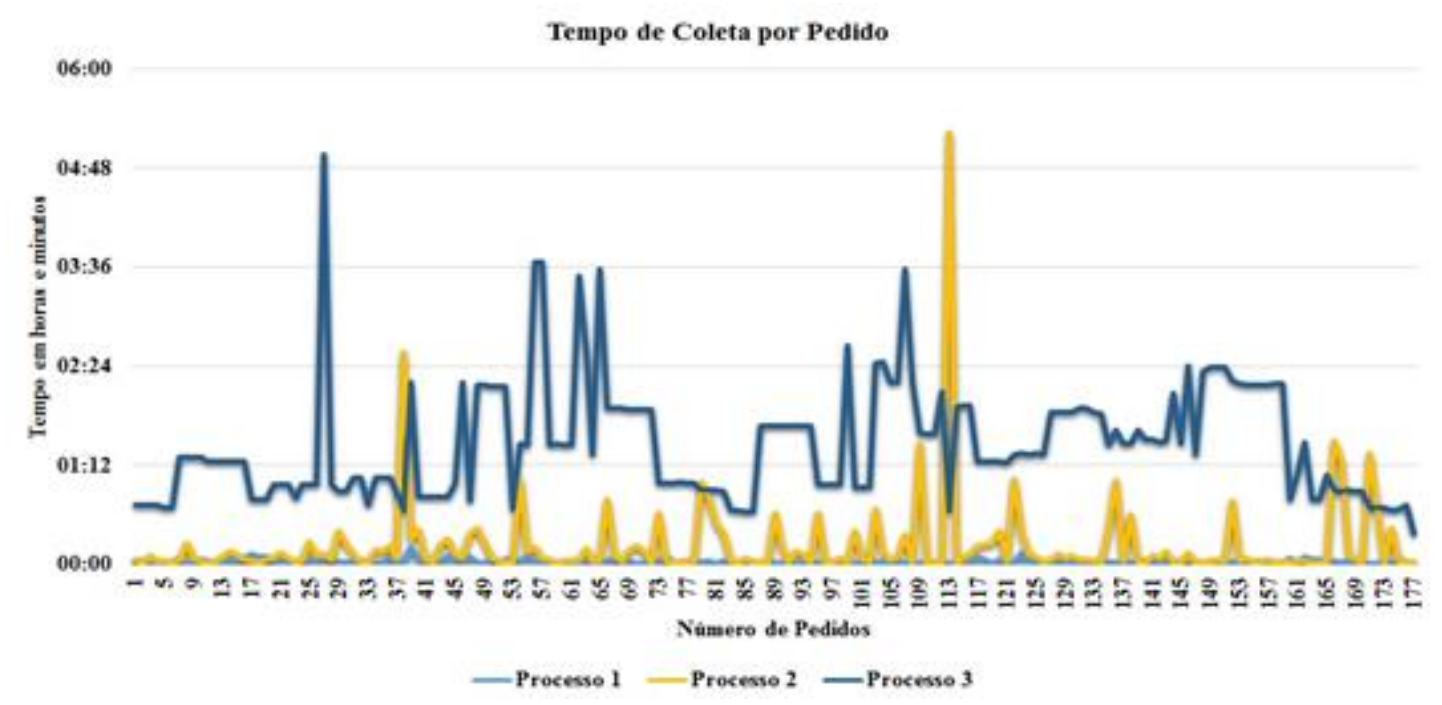

Fonte: Autoria Própria

- Processo 1: Corresponde ao momento que o cliente finaliza o pedido no atendimento, gerando uma comanda de serviço, fazendo que o colaborador responsável no setor de entregas imprima essa comanda e verifica o que foi solicitado pelo cliente. A média desse processo é de 1 minuto.

- Processo 2: É realizado quando o colaborador já fez o frete de loja, ou seja, quando ele buscou na loja os produtos do cliente, checou eles no sistema e emitiu financeiramente o cupom fiscal para o cliente, finalizando o pedido à disposição para entrega, na cesta de saída. A média desse processo é de 13 minutos. 
- Processo 3: É o tempo que o entregador leva para entregar o pedido na casa do cliente, assim que este é liberado. A logística de entrega é de responsabilidade exclusivamente do entregador, a única regra que a coordenação imediata solicitou aos mesmos foi que não misturassem os setores de entrega.

A Figura 11 representa coleta de dados de 177 entregas, com o pico de pedidos a partir das 9:30 horas até as 15:30 horas.

Figura 11 - Coleta de dados de solicitação de pedidos

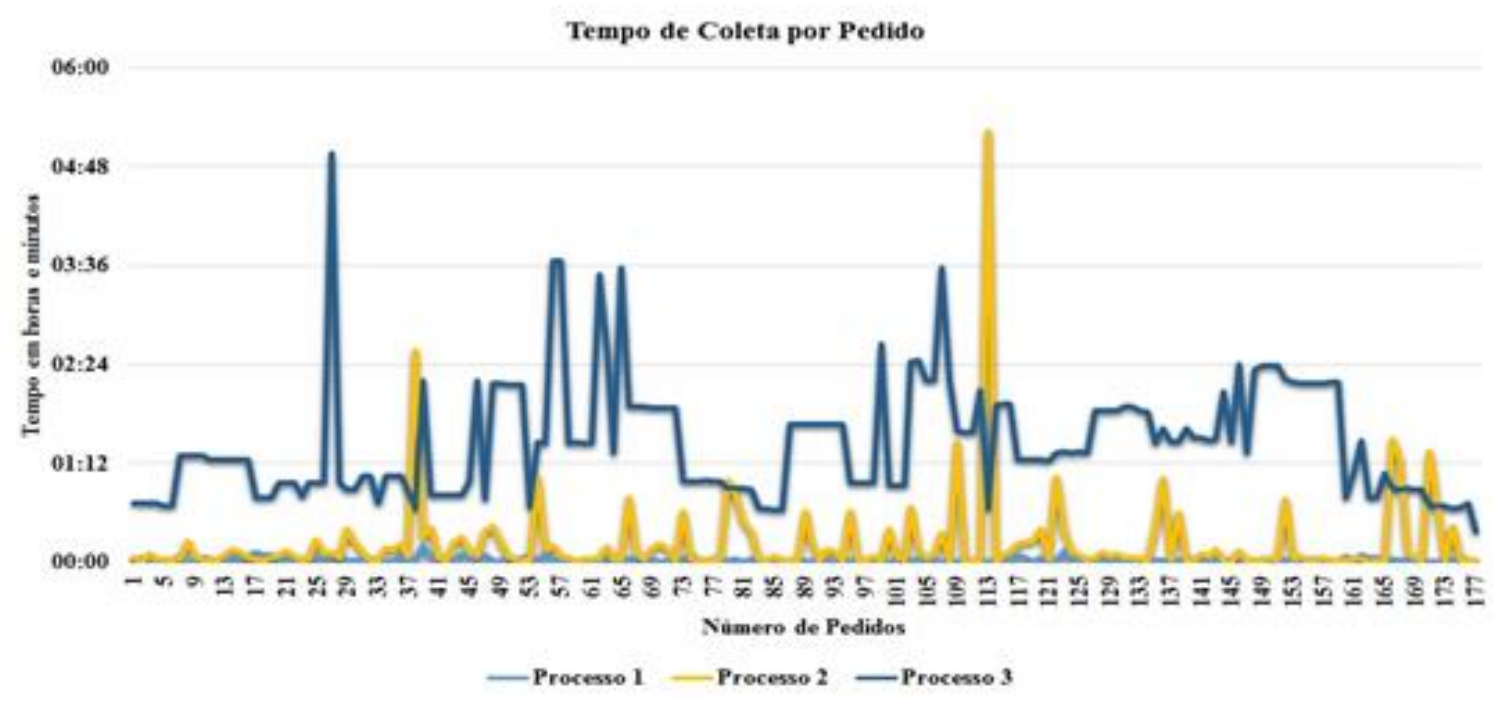

Fonte: Autoria Própria

Verifica-se que o processo 1 não demora tanto, mas que o gargalo da operação está na verdade, no processo 3 , de entrega do pedido, com picos inconstantes acima de 1 hora, tendo um pedido nesse dia de trabalho passando de 4 horas, averiguou que este pedido ficou parado no setor porque o endereço estava incorreto e o cliente não atendia o telefone de contato informado no atendimento para confirmar o endereço.

No processo 2 que poderia ser um processo mais rápido, com média de execução de 13 minutos, o indicador maior para abaixar esse número seria o melhor treinamento do colaborador da área no quesito medicamentos e suas derivações, fazendo que diminui os retrabalhos. No caso apresentado um pedido chegou por mais de 4 horas, trata-se de uma falta de medicamento na loja, neste caso foi acionado o mensageiro que se dirigiu na loja para buscar o medicamento.

A Figura 12, refere-se a análise da última etapa do processo, nesse caso é de 1:16 horas. O tempo de espera dentro da loja varia muito no decorrer do dia de trabalho, não tem uma linearidade de tempo. 
Figura 12 - Coleta de dados de solicitação de pedidos tempo final

\section{Tempo de Coleta por Pedido}

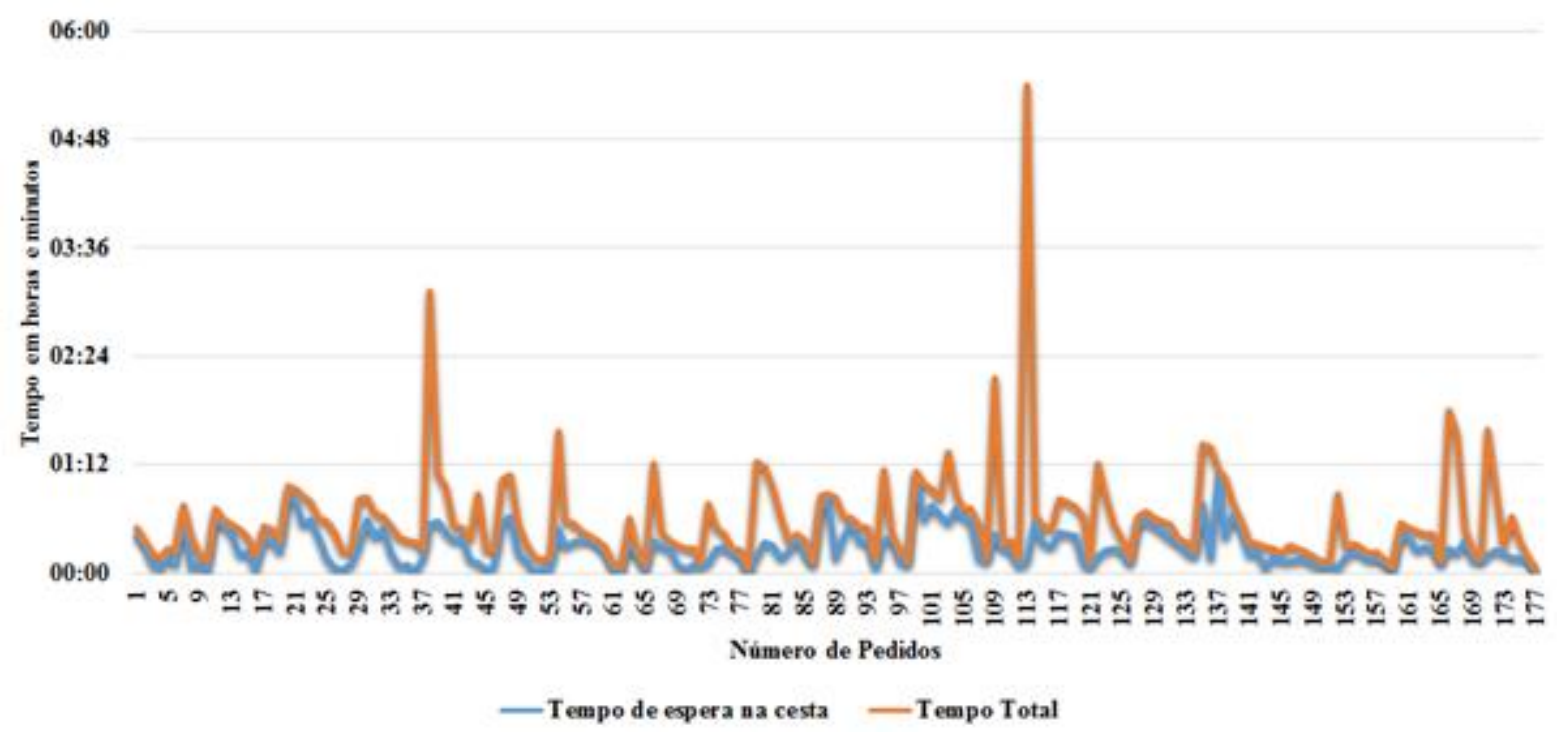

Fonte: Autoria Própria

A maioria dos pedidos estão em torno de 1:00h de entrega. Todo processo exige muitas habilidades específicas do colaborador, somado com atenção no que envia para o cliente, por se tratar na maioria dos pedidos de medicamentos.

\subsection{Análise de Consistência e Precisão dos Métodos}

Para validar as metodologias apresentadas nesse trabalho, foi utilizado um modelo de simulação discreta, utilizando o programa de simulação Anylogic®. Foi discutido com a equipe de entrega e o coordenador imediato as ações para melhoria do setor a fim de diminuir e otimizar o processo de entrega. Sendo assim, foram sugeridos: novo treinamento do colaborador que realiza o processo de separação, checkout e conferência dos pedidos, para a diminuição da taxa de ocupação do mesmo, troca de horário de chegada do terceiro entregador para suprir o horário de pico de pedidos e diminuir a taxa de ocupação dos dois entregadores que estavam sobrecarregados, novo roteamento de setores, para a não divergências dos entregadores em relação aos endereços e por fim um novo procedimento operacional para o atendimento de televendas, com o objetivo de evitar reentregas devido à falta de informações ou informações divergentes entre os setores de televendas e entregas. 


\section{Conclusão}

A proposta do presente trabalho foi realizada com pontos satisfatórios. A central de atendimento foi padronizada, a forma de cadastro do cliente, o que reduziu significativamente em pouco tempo os impactos negativos na entrega do pedido para o cliente. No mesmo sentido, com a valorização da cultura da empresa, apresentados para a equipe através das ferramentas de qualidade, bem como teve se a oportunidade de mapear os processos inerentes a cada atividade, possibilitando assim mensurar com dados factíveis à tomada de decisão pela gerência da empresa. As mudanças foram justas e necessárias tanto internas como externas nesse caso com a empresa terceirizada de entrega, assim possibilitou diminuir o tempo de entrega de 2 horas e 20 minutos para 55 minutos em qualquer lugar da cidade de ItuiutabaMG. Novos procedimentos foram realizados, mantendo a excelência no atendimento na rede de farmácia analisada. Para sugestões de futuros trabalhos, propomos melhorias internas que não foram realizadas, como aumento do espaço físico do setor de entregas e maior remuneração da empresa terceirizada de entrega a fim de viabilizar a contratação de mais entregadores, fazendo que o processo de entrega ocorra em um menor tempo do que já foi obtido.

\section{REFERÊNCIAS}

Bernardi, L. A. Manual de Plano de Negócios: Fundamentos Processos e Estruturação. 2.Ed. São Paulo: Atlas 2009.

Carpinetti, L.C.R., Gestão Da Qualidade - Conceitos e Técnicas. São Paulo, Atlas, 2010

Laurindo, F. J. B.; Rotondaro, R. G. Gestão Integrada de Processos e da Tecnologia da Informação. São Paulo: Atlas, 2006.

Marconi, M. A.; Lakatos, E. M. Fundamentos da Metodologia Científica. São Paulo: Atlas, 2003.

Mello, C. H. P. ISO 9001:2008, Sistema de Gestão da Qualidade para Operações de Produção e Serviços. São Paulo:Atlas, 2011.

Oliveira, S. B.; Almeida Neto, M. A. Análise e Modelagem de Processos. In: Valle, R.; Oliveira, S. B. (Org.) Análise e Modelagem de Processos de Negócio: Foco na Notação BPMN - Business Process Modeling Notation. São Paulo: Atlas, 2009.

Paladini, E. P. Gestão da Qualidade: Teoria e Prática. São Paulo: Atlas, 2012.

Slack, N.; Chambers, S.; Johnston, R. Administração da Produção. 3 Ed. São Paulo: Atlas, 2009. 